\title{
Sağlık Bilimlerine Psikolojinin Büyük Katkı Yapacağı Bir Alan: Sağlık Psikolojisi
}

\author{
Ayşenur Aktaş@, Yeşim Korkut $\odot$
}

Acıbadem Mehmet Ali Aydınlar Üniversitesi, Psikoloji, İstanbul, Türkiye

Ayşenur Aktaş, Dr. Yeşim Korkut, Prof. Dr.

Iletişim:

Prof. Dr. Yeşim Korkut

Acıbadem Mehmet Ali Aydınlar Üniversitesi, Psikoloji, İstanbul, Türkiye

Tel: +90 2165004265

E-Posta:yesim.korkut@acibadem.edu.tr
ÖZET

Sağlık Psikolojisi, ilk kez 1978 yılında Matarazzo tarafından tanımlanmış olup sağlığın geliştirilmesi ve sürdürülmesini, hastalıkların ve ilgili işlev kayıplarının azaltılmasını ve psikoterapisini amaçlayan psikolojinin oldukça genç bir alanıdır. Kronik hastalıklara yaşam süresince artık daha sık rastlanması, zaman içinde hastalıklar üzerindeki biyolojik ve fizyolojik etkenlerin yanı sıra psikolojik faktörlerin de etkili olduğunun görülmesi, artan araştırmalar ve sağık hizmetleri içinde psikologların daha fazla yer almaya başlaması sağlık psikolojisinin doğmasını sağlayan önemli etkenler olmuştur. Sağlık psikologları önleyici çalışmaların (kadın sağlığı, yeme bozuklukları, sigarayı bırakma birimleri) yanı sıra hastanelerde farkı birimlerde (onkoloji, ağrı yönetimi, diyaliz), rehabilitasyon ve ağrı merkezlerinde çalışabilmektedirler. Davranışsal değerlendirmeler, klinik görüşmeler ve psikoterapötik müdahaleler yapabilmektedirler. Bununla birlikte sağlığın geliştirilmesi ve sürdürülmesi amacıyla kamu politikası çalışmalarına da katkıda bulunabilmektedirler. Üniversitelerin Psikoloji bölümlerinde, Tıp ve Sağlık Bilimleri Fakültelerinde araştırmacı, eğitimci olarak yer alabilmektedirler. Sağılı psikolojisi eğitiminde özellikle Amerika Birleşik Devletlerinde belli bir standardizasyon oluşturulmaya çalışılmaktadır. Türkiye'de çok yaygın olmamakla birlikte sağlık psikolojisi alanına yönelik yüksek lisans ve doktora eğitimleri denenmektedir. Giderek artan araştırmalar ve sağılı psikologlarının farklı düzeylerde sağlığa katkısı sayesinde alana duyulan ilgi de artmaktadır.

Anahtar sözcükler: Sağlık psikolojisi, sağlık bilimleri, önleyicilik, lisansüstü eğitim

\section{HEALTH PSYCHOLOGY: AN AREA OF PSYCHOLOGY WHICH WILL HAVE A GREAT CONTRIBUTION TO HEALTH SCIENCES}

\section{ABSTRACT}

Health Psychology was first described by Matarazzo, and it is a relatively new field of psychology aiming at the reduction of illnesses and related dysfunctions and "via psychotherapy" promoting the development and maintenance of health. The increasing frequency of chronic illnesses throughout life, the understanding of the impact of psychological factors as well as the biological and physiological factors on diseases, increasing the body of research and the involvement of psychologists in health services have been all become important factors in the emergence of health psychology. Health psychologists can do preventive work (women's health, eating disorders, smoking cessation units), or they can work at various clinical departments in hospitals (oncology, pain management, dialysis units) or in rehabilitation and pain centers Pain Rehabilitation Center (PRC). They can conduct behavioral evaluations, clinical interviews and psychotherapeutic interventions. They can contribute to public policy studies to develop and maintain health. They can work in departments of psychology at universities as researchers and educators in Faculty of Medicine or Health Sciences. Especially in the USA, a standardization is being tried to be established in health psychology education. Although not very common in Turkey, master degree programs and doctoral studies of Health Psychology have been tried. Due to increasing research and health psychologists' contribution to health at different levels, the interest in the field is also increasing.

Keywords: Health psychology, health sciences, prevention, postgraduate education
Gönderilme Tarihi : 16 Mart 2018

Revizyon Tarihi : 16 Mart 2018

Kabul Tarihi : 30 Eylül 2018 


\section{Sağlık psikolojisi tanımı, amaçları, alt alanları}

Psikolojinin en genç alt alanlarından biri olan Sağlık Psikolojisi, resmi anlamda ilk kez Amerikan Psikoloji Birliği (APA) tarafından bir birim olarak (Division 38) 1978 yılında tanınmıştır. Sağlık psikolojisi biriminin kurulmasından sonra APA'nın ilk başkanı Matarazzo (1980) sağlık psikolojisini 'sağlığın geliştirilmesi ve sürdürülmesi, hastalıkların ve ilgili işlev kayıplarının azaltılması ve tedavisi için psikoloji disiplininin kendine özgü eğitimsel, bilimsel ve mesleki katkılarının toplamı' olarak tanımlamıştır (1).

Tarihsel perspektifle bakıldığında bulaşıcı hastalıkların azalması, kronik hastalıkların artmaya başlaması, sağlık hizmetlerinin gittikçe yaygınlaşması, psikologların sağlık hizmetleri içindeki öneminin görülmeye başlanması, hastalıklar üzerinde ruhsal ve toplumsal faktörlerin de etkili olabileceği görüşü sağlık psikolojisi alanına olan gereksinimi doğurmuştur (2). Bu doğrultuda biyopsikososyal modelin oluşturduğu zemin üzerine sağlık psikolojisi alanı yavaş yavaş kendini göstermeye başlamıştır.

Sağlığı bir bütün olarak ele alan, psikoloji ve sağlık arasında dolaylı ve doğrudan bağlantılar olduğunu ileri süren sağlık psikolojisi, hastalıkların etiyolojisinde davranışların rolünü değerlendirmeyi, sağlıksız davranışları yordamayı, psikoloji ve fizyoloji arasındaki etkileşimi ele almayı, hastalık yaşantısında ve hastalığın tedavisinde psikolojinin rolünü ortaya koymayı amaçlamaktadır (3).

\section{Sağlık psikologları kimlerdir ve neler yaparlar?}

Önceleri tıbbi birimlerde büyük ölçüde klinik psikologlar çalışmakta iken daha sonra sağlık psikolojisi alanının resmen tanımlanması ve alana has yüksek lisans ve doktora programlarının açılmasını takiben bu durum bazı ülkelerde değişmiştir. Örneğin, Amerika Birleşik Devletleri'nde (ABD) son yıllarda sağlık psikologlarının tıbbi ortamlardaki önemi ve yerinin gittikçe arttığl; rehabilitasyon, kardiyoloji, pediatri, onkoloji, diş hekimliği gibi multidisipliner klinik ve araştırma ekiplerinin önemli bir parçası haline geldikleri görülmektedir (4).

Sağlık Psikolojisi alanında çalışan psikologlar, bugün, dört temel alanda çalışmalarını sürdürmektedirler:

1. Sağlığı geliştirmek ve korumak

2. Hastalığın önlenmesi ve tedavisi

3. Hastalıkların etiyolojisi konusunda araştırmalar yapmak

4. Sağılı politikalarına ve sağlık sistemine katkıda bulunmak (5).
Sağlık psikologlarının birçoğu ya klinik kapasiteleri doğrultusunda hastalar, hasta yakınları ve tıbbi ekiple doğrudan çalışarak ya da akademik ve araştırma becerilerini kullanarak alana katkıda bulunmaktadırlar. Bazıları da hem araştırmacı hem de uygulamacı olarak hizmet vermektedir. Hastaneler temel çalışma ortamlarından birisi olmakla birlikte daha önce belirtildiği gibi rehabilitasyon ve ağrı merkezlerinde de görev yapabilmektedirler. Bununla birlikte bazı sağlık psikologları onkoloji, ağrı yönetimi, kadın sağlığı, yeme bozuklukları, sigarayı bırakma programları gibi belirli sağlık bakım alanında uzmanlaşmış ortamlarda çalışmaktadırlar. Ayrıca üniversitelerin Psikoloji bölümlerinde, Tıp ve Sağlık Bilimleri Fakültelerinde uygulamalı ve araştırma bazlı çalışmalar yürütmektedirler.

Genellikle klinik ve tıbbi ortamlarda davranışsal değerlendirmeler, klinik görüşmeler, psikoterapötik müdahaleler ve kişilik testleri yapan sağlık psikologları, önleyici ve eğitici çalışmalar, araştırmalar ve kamu politikası çalışmaları da planlamakta ve içinde yer alabilmektedirler. Sağlık psikologlarının çalışmalarına daha yakından bakmak gerekirse örneğin klinik ortamlarda çalışan sağlık psikologları hastalık sürecinde tedavi uyumunu, hastalığın doğasından kaynaklı bireyin, ailesinin ve tedavi ekibinin karşılaştıkları zorlukları, bu sürecin getirdiği psikososyal sorunları ele alır ve çözümler üretirler. Bununla birlikte sadece hastalık sürecinde değil hastalık öncesinde de bireyin hangi olumsuz sağlık davranışlarının hastalığa sebep olduğunu inceleyerek bunların değiştirilmesi ile ilgili olarak çalışırlar. Bunların yanında sağlığın geliştirilmesi ve sürdürülmesini ele alan çalışmalar da yaparlar. Bu çalışmalar birincil ve ikincil önleyici çalışmalar olarak düşünülmektedir. Hastalıkların çıkış nedenleri ve bu nedenler üzerindeki psikososyal etkenleri araştırmak da sağlık psikologlarının temel çalışma konuları arasındadır.

Sağlık psikolojisi içerisinde zamanla birtakım özel uzmanlık alanları da oluşmuştur:

Klinik Sağlık Psikolojisi: Sağlık psikolojisinin bu alt alanı, klinik psikoloji ile güçlü bir bağlantıya sahiptir ve psikoterapi, davranış değişikliği ve sağlık eğitimi gibi faaliyetleri içerir (4).

İs Sağlığı Psikolojisi: Sağlık psikolojisinin bu alt alanı endüstriyel psikoloji ve ilgili disiplinleri içermektedir. İ̧ sağlığı psikologları, iş yerindeki konuların fiziksel ve zihinsel hastalıklarla nasıl bağlantılı olduğunu anlamaya odaklanır (6).

Topluluk Sağlık Psikolojisi: Sağlık psikolojisinin bu alt alanında çalışan kişiler genellikle topluluk düzeyinde müdahale ve önleme tekniklerini geliştirmeye odaklanırlar. Bu 
profesyoneller, sağlıklı davranışları veya davranış değişikliğini teşvik etmek amacıyla toplulukların değerlendirmelerini yapabilir veya gruplarla çalışabilir (7).

Halk Sağlığı Psikolojisi: Bu alt alandaki sağlık psikolojisi uzmanları, hastalık-sağlık oranlarını nüfus düzeyinde anlama üzerine yoğunlaşmaktadır ve genellikle sağlık profesyonellerine, devlet kurumlarına ve sağlık eğitimcilerine tavsiyeler sunmaktadırlar (8).

\section{Sağlık psikologlarının eğitimi}

$A B D$ 'de üniversitelerin üçte birinde lisans düzeyinde sağlık psikolojisi dersleri verilmektedir. Yüksek lisans programları ise oldukça çeşitlidir. Bazıları tamamen sağlık psikolojisi alanı için tasarlanmışken bazıları da sağlıkla ilgili dersleri içermekle birlikte klinik ve sosyal psikoloji için eğitim sunarlar. Psikolojinin temel alt alanlarına nazaran daha yeni gelişmekte olan Sağlık Psikolojisinin eğitiminde de zamanla bir standardizasyon oluşturulmaya çalışılmaktadır. Sağlık Psikolojisi programlarının içeriğinde araştırma yöntemleri, sağlık ve hastalığın biyopsikososyal süreçleri, sağlık sistemi gibi dersler bulunmaktadır. Doğrudan klinik hizmet verecek olan sağlık psikoloğu adayları için ise fizyoloji ve farmakoloji gibi tıbbi dersler vardır. Bununla birlikte öğrencilerin sağlık sistemi içinde psikolog olarak etkin bir şekilde işlev gösterebilmeleri için epidemiyoloji, biyoistatistik, halk sağlığı bilmelerinin de gerekli olduğu düşünülmektedir (9). ABD'de artık düzinelerce özelleşmiş sağlık psikolojisi programı vardır. Bu programlar bir akreditasyon süreci vasıtasıyla gözden geçirilir ve sağlık psikologları tipik olarak doktora derecelerini bu alanda alabilirler. Diğer yandan doktoralarını farklı alanlarda almış kişiler için ise 'doktora sonrası' programlar bulunmaktadır (5).

Kanada'da 2000 yılında yapılan inceleme sonucunda psikoloji bölümlerinin \%31'inde sağlık psikolojisinde uzmanlaşmış tek bir fakülte üyesinin dahi olmadığı belirtilmektedir. Psikoloji bölümlerinin ise \%47'sinde sağlık psikolojisi konusunda tek bir ders yoktur (10). Dolayısıyla sağlık psikolojisi alanının Kanada'da daha az gelişmiş olduğu düşünülmektedir. Bununla birlikte Avrupa'da sağlık psikolojisinin en fazla gelişim gösterdiği ülkelerden biri ise İngiltere'dir (11, 12).

\section{Ülkemizde sağlık psikolojisinin gelişimi}

Sağlık Psikolojisi, Türkiye'de çok yeni gelişen bir alan olduğundan henüz çok az sayıda üniversitenin Psikoloji bölümlerinde Sağlık Psikolojisi ile ilgili dersler verilmektedir. Lisansüstü eğitim standartları konusunda üzerinde hem fikir olunmuş bir müfredat çatısı yoktur ve düzenli açılan yüksek lisans ve doktora programları sayısı çok azdır. Türkiye koşullarında, tıpkı $A B D$ ve bazı Batı ülkelerinde yakın zamana dek sürdürüldüğü, hatta bazılarında hala sürmekte olduğu gibi Sağlık Psikolojisi Klinik Psikolojinin bir alt dalı olarak düşünülmektedir. Gelecekte özellikle YÖK tarafından tanınan lisansüstü programların açılması ile birlikte 'Sağlık Psikolojisi' daha çok tanınabilecektir.

Ülkemizde sağlık psikolojisi içeriğine sahip lisansüstü eğitimler gözden geçirildiğinde isim olarak sağlık psikolojisi olarak adlandırılmış ancak ama içerik olarak birbirinden farklı birçok yüksek lisans programları olduğu görülmüştür (13). Bu programlara Karadeniz Teknik Üniversitesi Sağlık Bilimleri Enstitüsü Sağlık Psikolojisi ve Ege Üniversitesi Sağlık Danışmanlığı yüksek lisans programları örnek gösterilebilir. Bizim anladığımız ve kabul ettiğimiz anlamda sağlık psikolojisi müfredatına sahip yüksek lisans programı ise iki özel üniversite tarafından denenmiş fakat sürdürülememiş olmakla birlikte şu an Kadir Has Üniversitesi'nde içeriği sağlık-sosyal psikoloji olan bir yüksek lisans programı bulunmaktadır. Sağlık psikolojisi içeriğinde üç öğrencinin kabul edildiği ilk doktora düzeyi* programı ise İstanbul Üniversitesi Sosyal Bilimler Enstitüsü bünyesinde açılmış ve halen İstanbul Üniversitesi'nde düzenli olarak sağlık psikolojisi müfredatındaki derslerle yüksek lisans ve doktora programları** açılmaktadır.

Lisansüstü eğitimlerin yanı sıra alandaki eğitim boşluğunu kapatmak amacıyla Türk Psikologlar Derneği tarafından hizmet içi eğitimler de (örn. Korkut, 2003, 2004) yapılmıştır (13) ve bir sefer 2006 yılında TPD İstanbul Şube tarafından organize edilen bir sertifika programı denenmiştir.

*Prof. Dr. Yeşim KORKUT koordinatörlüğünde, **Doç. Dr. H. Özlem SERTEL BERK koordinatörlüğünde

Sağlık psikolojisi alanında Türkçe yazılmış ilk kitap Doç. Dr. Ülgen Okyayuz tarafından yayınlanan Sağlık Psikolojisi kitabıdır (1998). Prof. Dr. Zuhal Baltaş tarafından hazırlanan 'Sağlık Psikolojisi: Halk Sağlığında Davranış Bilimleri' (2004) ve yazarı Jane Ogden olan ve yakın zamanda Türkçe'ye çevrilen 'Sağlık Psikolojisi' (2012) kitabı da bu alana ait yazılı kaynaklardır. Boratav ve Sunar tarafından yazılan 'Sağlık Psikolojisi: Türkiye Açısından Bir Durum Değerlendirmesine Doğru' derleme makalesi de ilk kaynaklara örnek verilebilir. Bunların yanında Orta Doğu Teknik Üniversitesi'nde Prof. Dr. Özlem BOZO tarafından yürütülen Sağlık Psikolojisi Araştırma Grubu ve İstanbul Üniversitesi Klinik-Sağlık Psikolojisi yüksek lisans ve doktora programlarında yapılan tezler ve makaleler ülkemizdeki 
sağlık psikolojisi literatürüne katkıda bulunmaktadırlar. Zira ülkemizde sağlık psikolojisi literatürü oldukça sınırlıdır. Örneğin, Er ve arkadaşları (2002) tarafından psikoloji alanında önde gelen yayınlardan biri olan Türk Psikoloji Dergisi üzerine yapılan bir çalışmada 1978 ile 2002 yılları arasında sağlık psikolojisi ile ilgili neredeyse bir sayıyı bile dolduramayacak kadar az yayın olduğu bulunmuştur (13). Derginin 2002'den günümüze kadar olan sürede yayınlanan sayıları incelendiğinde ise sağlık psikolojisi alanı ile ilgili olarak toplam 13 yazının olduğu görülmüştür.

\section{Gelecekte sağlık psikolojisini neler bekliyor?}

Psikoloji alt dalları arasında henüz yeni filizlenen Sağlık Psikolojisinin gerek edindiği amaçlar gerek hizmet ettiği alanlar göz önünde tutulduğunda ülkemizdeki sağlık sistemine büyük katkılar sağlayacağı düşünülmektedir. Ancak, Sağlık Psikolojisinin gelişimine ivme kazandırabilmek adına bir takım çalışmaların yapılması gerekmektedir. Öncelikle lisans müfredatlarında sağlık psikolojisi konulu derslerin artması, gelecekte özgül olarak YÖK tarafından

\section{Kaynaklar}

1. Matarazzo J. D. Behavioral health and behavioral medicine: Frontiers for a new health psychology. American psychologist, 1980;35:807-17.

2. Okyayuz Ü. H. Sağlık psikolojisi. Ankara: Türk Psikologlar Derneği Yayınları, 1999: 1-19.

3. Ogden N. Sağlık Psikolojisi (G. Dirik, Çev.). Ankara: Nobel Akademik Yayıncılık, 2016: 1-14.

4. Nezu A.M., Nezu C.M., P.A. Geller. Handbook of psychology, volume 9 health psychology, John Wiley\&Sons. 2003: 5-27.

5. Sarafino E. Health Psychology. Biophysical Interactions. New York, John Wiley \& Sons, Inc, 1998.

6. Quick J.C. Occupational health psychology: historical roots and future directions. Health Psychol. 1999;18:82-8.

7. Campbell C. Community health psychology: promoting analysis and action for social change. Journal of health psychology. 2004;9:18795. [CrossRef] tanınan 'Sağlık Psikolojisi' başı̂ılı yüksek lisans ve doktora programlarının açılması ve bu programların akredite edilmesi gereklidir. Zaman içerisinde bilhassa, tezli lisansüstü programlarda yürütülen çalışmalarla alana ait araştırmalarda kullanılacak ölçeklerin geliştirilmesi çok yararlı olacaktır. lyyi yetişmiş sağlık psikologların tıbbi ortamlarda ve ekiplerde yer almasının teşvik edilmesi ve desteklenmesi sağlık psikologlarının tıbbi ekipler tarafından tanınması adına oldukça önem taşımaktadır. Diğer sağlık çalışanlarının alanı daha iyi tanıyabilmesi için Sağlık Psikolojisi hakkında bilgilendirilmeleri oldukça önemlidir. Bu doğrultuda özellikle Tıp Fakültelerinin müfredatlarında da sağlık psikolojisi ile ilgili derslerin yer alması henüz eğitim aşamasında iken geleceğin sağlık çalışanlarına ulaşabilmek adına faydalı olacaktır.

Sonuç olarak, bu alan ile ilgili olarak yapılan çalışma sayılarının, lisansüstü programlarının artması gelecekte sağlık psikologlarının sağlık alanına olan katkısının günümüze kıyasla çok daha fazla olacağını düşündürmektedir.

8. Hepworth J. Public health psychology: a conceptual and practical framework. J Health Psychol. 2004;9:41-54. [CrossRef]

9. Weiss S. M. Health psychology and other health professions. in Stone, G. C. (Ed.). Health psychology: A discipline and a profession. University of Chicago Press, 1987:61-75.

10. Arnett J. L. Clinical and health psychology: Future directions. Canadian Psychology/Psychologiecanadienne. 2001;42:38.

11. Krespi R., Bone M., Ahmad R., Worthington B., Salmon P. Haemodialysis patients' beliefs about renal failure and its treatment. Patient Education and Counseling. 2004;53:189-96. [CrossRef]

12. Salmon, P., Hill J., Krespi R., Clark L., Fisher J., Holcombe C.. The role of child abuse and age in vulnerability to emotional problems after surgery for breast cancer. European Journal of Cancer. 2006;42:251723. [CrossRef]

13. Boratav H. B., Sunar D. Sağlık Psikolojisi: Türkiye Açısından Bir Durum Değerlendirmesine Doğru. Psikoloji Çalışmaları Dergisi 2005;25:1-18. 